\title{
Sexual Commerce: Troubling Meanings, Policies, and Practices
}

\author{
Isabel Crowhurst ${ }^{1}$ (ID $\cdot$ Niina Vuolajärvi ${ }^{2} \cdot$ Kathryn Hausbeck Korgan $^{3}$
}

Published online: 13 April 2019

(C) Springer Science+Business Media, LLC, part of Springer Nature 2019

This special issue on Sexual Commerce: Troubling Meanings, Policies, and Practices aims to intervene in contemporary debates over the marketplace of sex for sale by presenting new research on trends in commercialized sex and its regulation, as embedded in wider social, political, and economic practices. As the global sex industry is growing in size and visibility, new forms of commercial sexual exchange are emerging as a problem of governance, internationally and nationally. Here, we explore and interrogate laws and policies as inseparable dimensions of social relations that operate alongside other discourses and practices (Scoular 2015), and as firmly embedded in the power dynamics of global economic structures.

Some of the questions that animate this issue include the following: how is sex work understood in the twenty-first century? What are the processes that contribute to ascribing and shifting the meanings of sex for sale? What do laws and policies $d o$ and how do they affect experiences, practices, and spaces of sex work across different regions and local contexts? How can we understand social and cultural norms that inform sex work in the context of the forces of a globalized economy? In addressing these interrelated questions, contributions to this special issue reveal the complexity of sex work and contrast it to pervasive simplifications and misrepresentations that tend to understand and treat it as an aberration, a deviant phenomenon that sits at the margins of society and economic structures. Moreover, women who sell sex are cast as either victims or deviants, and clients,are stereotyped as men who have a distorted notion of normal and healthy sexuality. Within this

Isabel Crowhurst

icrow@essex.ac.uk

1 Department of Sociology, University of Essex, Wivenhoe Park, Colchester CO4 3SQ, UK

2 Department of Sociology, Rutgers University, New Brunswick, NJ, USA

3 Department of Sociology, University of Nevada, Las Vegas, NV, USA frame of understanding, doing the "right thing" about prostitution is viewed as a matter of national values and a moral imperative which entail, more often than not, the rigid policing of the boundaries between markets and sexual/intimate domains (Zelizer 2005). This special issue recognizes the paradigmatic nature of these radical simplifications and seeks to move beyond the trans-historical treatment of prostitution as homogeneous and universally problematic. The analyses presented, while not offering a global perspective, reveal and engage with a diversity of national contexts-Belgium, France, Brazil, Bulgaria, Finland, Italy, Kenya, Norway, Slovenia, Sweden, Switzerland, and the UK - and, with new insights, carry forward many of the themes emerging from the expanding field of sex industry research. In what follows, we expand on four aspects of commercial sex work that the nine contributions of this special issue shed light upon.

Firstly, a political economic analysis of sex work frames sexual markets as integrated into structures and hierarchies of global capitalism (Smith 2015) and as differently shaped by its regional and localized manifestations. We see this in the contribution by Amanda De Lisio, Philip Hubbard, and Michael Silk who, with a focus on Rio de Janeiro, explore how sport mega-events, as "rapacious convergence of global-corporate interest with the more locally embedded desire for foreign investment and tourism", change sexual landscapes and impact informal sexual economies. Problematically, this is often accomplished by targeting sexualized and racialized minorities who do not comply with middle-class tourist esthetics. In her study, Jane Pitcher emphasizes the importance of understanding the working experiences of indoor-based sex workers of different genders in Great Britain. She stresses the need to understand these aspects not only in the context of regulatory and policy backgrounds but also of increasing globalization of production and markets which have had significant impacts on the organization of the labor markets and transitions within it, including the informal sex economy. A similar point is also advanced by Roman Kuhar and Mojca Pajnik who show how, in the Slovenian post-socialist context, the meltdown of the welfare socialist regime shaped the lives, employment choices, and opportunities of the male sex workers they 
interviewed. Georgi Petrunov looks at the development and flourishing of elite prostitution in post-socialist Bulgaria in the context of unequal accumulation of wealth in a country which, despite being one of the poorest in the EU, has a powerful oligarchy and an extremely wealthy minority characterized by significant gender imbalances. In her analysis on the ambiguous taxation of prostitution in Italy, Isabel Crowhurst emphasizes the interplay of economics and morality by pointing out ways in which anxieties linked to economic crisis and accruing national debt can shift policy and political stances towards sex work.

A second related consideration emerging from all contributors to this special issue is that, as Giulia Garofalo Geymonat states, "over the last 20 years, the global sex industry has seen increased diversification, with new subjects coming into public light, as clients, as workers, and as so-called third parties organising or facilitating the trade." The brokers of elite prostitution that Petrunov explores in Bulgaria are an example of such developments, and so is the case explored by Garofalo Geymonat on the creation of specialized sex services, socalled sexual assistance, for people with disabilities. Fastchanging developments in digital technologies are also shifting significantly the spaces, modalities, and organization of sexual encounters and labor. As the study of Slovenian male sex workers reveals, these developments have resulted in more autonomy, but also in new risks which might reduce the sense of control over the organization and management of their labor. The intensification of transnational migrations and cross-border movements also accounts for the increasing presence of non-country nationals in many sex industries of economically developed countries, such as those of the Nordic region explored by Niina Vuolajärvi. Here, $70 \%$ to $80 \%$ of people who sell sex are migrants, but despite this, Vuolajärvi claims that "the role of immigration regulation is rarely addressed in political debates around the so-called Nordic model."

The latter consideration leads us to the third theme emerging from the contributions: the disparity as Pitcher puts it, "between dominant policy representations of sex workers and the working lives of people selling intimate services." This, Pitcher's study shows, has created a disjuncture that contributes to ignoring the needs and experiences of male and transgender sex workers and exacerbates the stigma experienced by all sex workers she interviewed. Similar processes of epistemic erasure are revealed by Kumar and Pajnik in the Slovenian case. The authors show how processes of retraditionalization, whereby religious and nationalist groups proclaim a return to "true national values" allegedly lost during the communist regime, are reinforcing hegemonic masculinities, patriarchal imaginaries, and homophobia which in turn contribute to ignoring men who sell sex to men. This has also implications on the typologies of service provision offered by non-governmental organizations (NGO) and the populations they target. The latter usually exclude male sex workers because they do not fit into the paradigm of prostitution as gendered exploitation of vulnerable women. The role of NGOs is also explored in detail by Marion David who traces the shifting approaches and ideologies towards sex work and prostitution in Belgium and France over time and their role in shaping public debates. Her comparative analysis of the "discordant evolutions" of third sector organizations' approaches to sex work in the two neighboring countries sheds light on political power struggles that developed around public health concerns related to HIV/AIDS. While in France the appearance of AIDS "has not transformed the public policy paradigm centred on stopping prostitution" and eventually strengthened the rehabilitative and neo-abolitionist agenda, in Belgium, this led to the implementation of social and medical support structures in collaboration with sex workers. In the Italian case discussed by Crowhurst, the Court of Appeal's ruling that declared prostitution as a legitimate economic activity has not been followed through in fiscal arrangement and other legal and policy measures. This reveals the complexity of policy processes and the disjuncture between and within legal systems as well as between elected officials, state agencies, implementing agencies - all factors that have concrete implications on the lives of sex workers. Relatedly, Naomi van Stapele, Lorraine Nencel, and Ida Sabelis present a poignant example of the inconsistency of state measures towards sex work: in the Kenyan context, they reveal, the government, on the one hand, works together with sex workers to distribute condoms while, on the other hand, it uses condoms as evidence to arrest them. Moreover, the need for horizontal partnerships between sex workers and government agencies that the government itself has explicitly discussed is only partially fulfilled in a country where sex work remains criminalized.

As mentioned above, many of the articles point out the simplifications underpinning state discourses on commercial sex. Reductionism perpetuates stigma and exclusion, especially when reproducing banalizing narratives of (female) sex. De Lisio et al. reveal this clearly in their discussion of the "discursive and material construction of those involved in sexual commerce as either 'deviant' or 'victim' in the humanitarian crusade known to follow the hypermasculine sport spectacle." The disconnect between policies and real lived lives, the pervasiveness of the victim-deviant binary, and their negative impacts also are evident in Vuolajärvi's article. Here, we see how the stated feminist-humanitarianism of the socalled Nordic model aimed at "prostituted victims" in practice leads to social welfare exclusions, evictions, and deportations of migrant sex workers who are targeted by punitive immigration policies. This is explained as a form of punitivist humanitarianism or governing in the name of caring.

The final theme that all the contributions highlight pertains to the widespread silencing and/or ignoring of sex workers' perspectives on issues that have a direct impact on their 
personal and professional lives. This erasure results from deeply ingrained assumptions and practices that reinforce the lesser status of sex workers as citizens who therefore cannot participate in public politics, again, because either too deviant or too vulnerable. Van Stapele et al.'s study of the tensions within daily practices of community participation of sex workers in Kenya exemplifies the difficulties - albeit not the impossibility — of organizing inclusivity in practice. As Picher states, drawing from Benoit et al. (2017), "while people may have limited options which make the notion of 'choice' contentious, this does not mean they have no agency at all." And, indeed, some of the contributions reveal the mobilization of individual and collective agency in strategies of resistance and engagement on the part of both sex workers and relevant actors, including NGOs, multi-scalar partnerships, and grassroots organizations.

As global demand for commercial sexual exchanges grows and becomes more visible, it is our hope that the contributions in this issue will advance research, support policies, and encourage legislative efforts that characterize sex work as plural, diverse, and enduring. Sexual commerce manifests the complexity of sex, gender, and markets in this high-tech, global, and neoliberal historical moment. Trans-historical, reductionist, protectionist, and prohibitionist approaches to understanding prostitution and sex work are doomed to fail, and it is workers who pay the high price of these indulgences. The authors in this volume recognize this through varied cultural lenses and document, in many different theoretical and methodological ways and diverse contexts, the critical importance of troubling the meaning of dominant prostitution policies and practices.

Acknowledgments The editors would like to thank our contributors for sharing their scholarly work in this special issue. We are especially grateful to the vibrant epistemic community that Prospol COST Action IS1209-“Comparing European Prostitution Policies: Understanding Scales and Cultures of Governance" built from 2013 to 2017. This special issue emerges from encounters, discussions, and collaborations facilitated by this network.

\section{References}

Benoit, C., Ouellet, N., Jansson, M., Magnus, \& Smith, M. (2017). Would you think about doing sex for money? Structure and agency in deciding to sell sex in Canada. Work, Employment and Society, 31(5), 731-747.

Scoular, J. (2015). The subject of prostitution. Abingdon, Oxon: Routledge.

Smith, N. (2015). The global political economy of sex work. In Steans and Tepe-Belfrage (Eds.), The handbook on gender in international relations (pp 370-377). Cheltenham, UK: Edward Elgar.

Zelizer, V. (2005). The purchase of intimacy. Princeton, NJ: Princeton University Press.

Publisher's Note Springer Nature remains neutral with regard to jurisdictional claims in published maps and institutional affiliations. 